
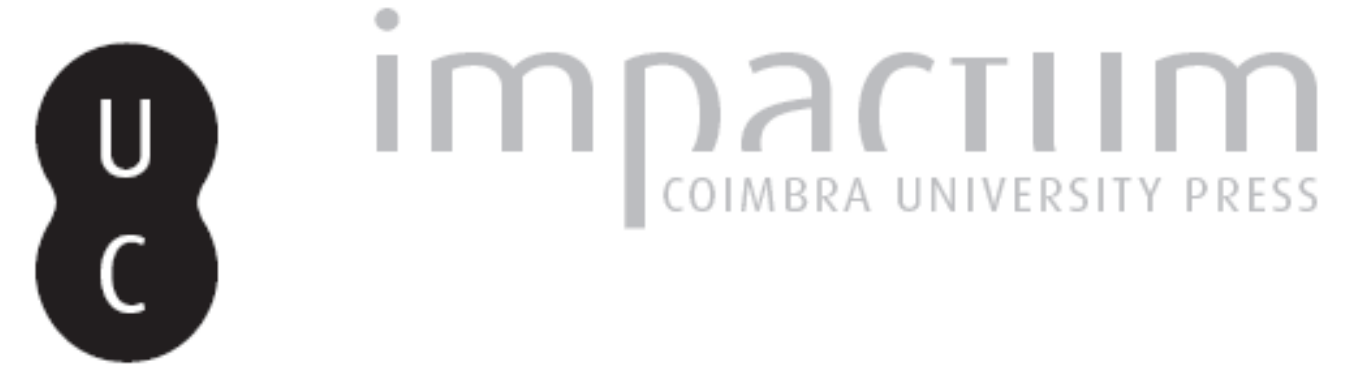

\title{
Que fenómenos estuda a teoria da argumentação?: em que consistem as suas tarefas descritivas?
}

Autor(es): $\quad$ Grácio, Rui Alexandre $\begin{array}{ll}\text { Publicado por: } & \text { Faculdade de Letras da Universidade de Coimbra, Instituto de Estudos } \\ & \text { Filosóficos }\end{array}$

URL

persistente:

DOI: $\quad$ DOI:http://dx.doi.org/10.14195/0872-0851_33_5

Accessed : $\quad$ 26-Apr-2023 15:06:05

A navegação consulta e descarregamento dos títulos inseridos nas Bibliotecas Digitais UC Digitalis, UC Pombalina e UC Impactum, pressupõem a aceitação plena e sem reservas dos Termos e Condições de Uso destas Bibliotecas Digitais, disponíveis em https://digitalis.uc.pt/pt-pt/termos.

Conforme exposto nos referidos Termos e Condições de Uso, o descarregamento de títulos de acesso restrito requer uma licença válida de autorização devendo o utilizador aceder ao(s) documento(s) a partir de um endereço de IP da instituição detentora da supramencionada licença.

Ao utilizador é apenas permitido o descarregamento para uso pessoal, pelo que o emprego do(s) título(s) descarregado(s) para outro fim, designadamente comercial, carece de autorização do respetivo autor ou editor da obra.

Na medida em que todas as obras da UC Digitalis se encontram protegidas pelo Código do Direito de Autor e Direitos Conexos e demais legislação aplicável, toda a cópia, parcial ou total, deste documento, nos casos em que é legalmente admitida, deverá conter ou fazer-se acompanhar por este aviso.

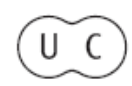




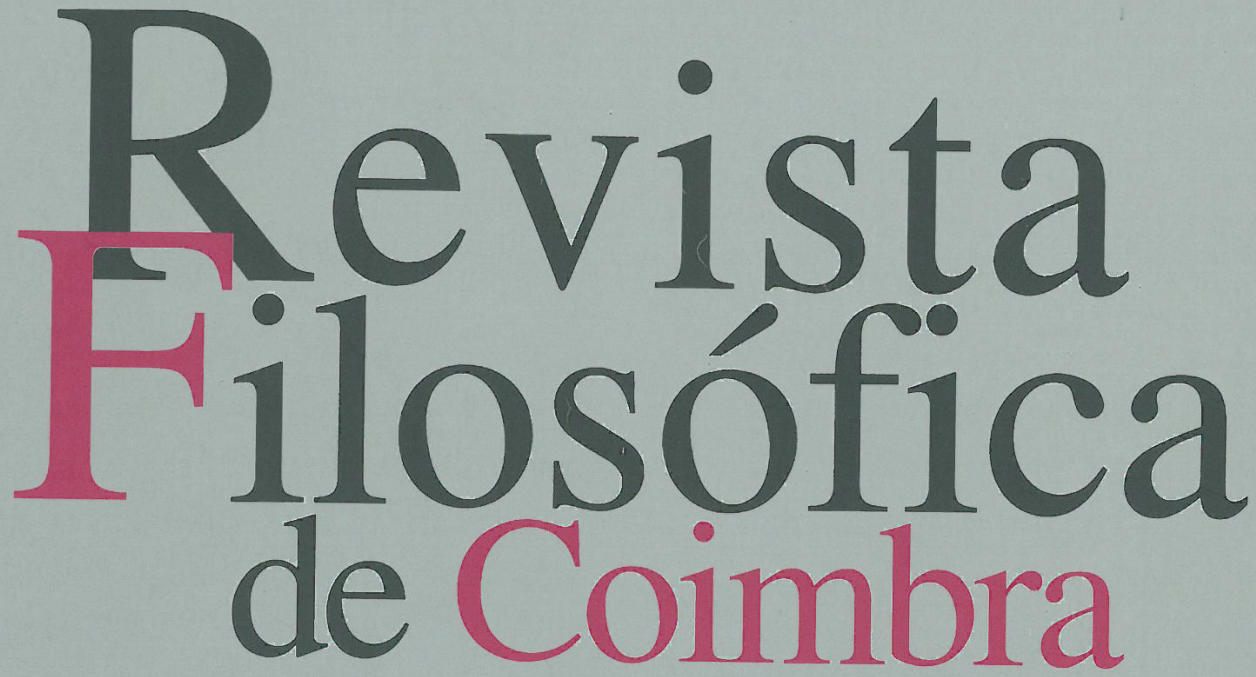

vol.17| n. .33 | 2008

Mário Santiago de Carvalho Fernanda Bernardo Luís António Umbelino Jean-Christophe Goddard Rui Alexandre Grácio Artur Ramos Luís M. Augusto Maria Luísa Portocarrero Jérôme Porée Diogo Ferrer Cláudio Alexandre Carvalho 


\title{
QUE FENÓMENOS ESTUDA A TEORIA DA ARGUMENTAÇÃO? EM QUE CONSISTEM AS SUAS TAREFAS DESCRITIVAS?
}

\author{
RUI ALEXANDRE GRÁCIO \\ (Fundação para a Ciência e a Tecnologia) \\ Em homenagem a Christian Plantin
}

\section{Resumo:}

Partindo do «modelo dialogal» proposto por Christian Plantin e da sua definição de argumentação, procura-se neste artigo sugerir alguns conceitos essenciais para a análise das argumentações e contribuir para uma perspectiva de resposta às seguintes perguntas: a) Que tarefas descritivas poderão ser levadas a cabo por um analista da argumentação e como é que elas se ligam com a questão crítica da avaliação dos argumentos? b) Que procedimentos metodológicos poderão servir de base a uma didáctica da argumentação?

Palavras-chave: interacção argumentativa, assunto em questão, tematização, perspectivas, raciocínios, crítica.

\section{Résumé:}

En partant du «modèle dialogal» proposé par Christian Plantin et de sa définition de l'argumentation, nous essayons de présenter quelques concepts essentiels pour l'analyse des argumentations et d'apporter une perspective de réponse aux questions suivantes: a) Quelles sont les démarches descriptives d'un analyste de l'argumentation et comment se relient-t-elles à la question critique de l'évaluation des arguments? b) Quelles procédures méthodologiques pourront fonder une didactique de l'argumentation?

Mots-clé: interaction argumentative, sujet en question, thématisation, perspectives, raisonnements, critique.

«De uma forma geral, como construir os instrumentos de uma crítica do discurso argumentativo, instrumentos sem os quais o 'espírito crítico' se arrisca fortemente a ficar vazio?»1

\footnotetext{
1 «D'une façon générale, comment construire les instruments d'une critique du discours argumentatif, instruments sans lesquels 'l'esprit critique' risque fort de tourner vide?»
} 
No artigo intitulado Análise crítica do discurso argumentativo, e após deslocalizar o seu estudo do «na língua» ${ }^{2}$, Christian Plantin escreve que a argumentação é:

«uma forma de interacção problematizante formada por intervenções orientadas por uma questão» ${ }^{3}$.

Trata-se, a meu ver, de uma das mais conseguidas aproximações a uma definição do objecto de uma teoria geral da argumentação, na medida em que, inserindo-se numa perspectiva que pretende proceder a «uma revisão sobre o que é fundamentalmente um dado em argumentação» ${ }^{4}$, permite delimitar autonomamente os fenómenos a descrever por esta teoria.

Sendo assim - e porque talvez o maior tributo que se possa prestar a um teórico seja o de nos interessarmos pelas suas investigações - um conjunto de reflexões sobre, e a partir, da definição apresentada poderá ajudar a aprofundá-la, a clarificá-la e a explicitar: a) Que tarefas descritivas poderão ser levadas a cabo por um analista da argumentação e como é que elas se ligam com a questão crítica da avaliação dos argumentos? b) Que procedimentos metodológicos poderão servir de base a uma didáctica da argumentação? ${ }^{5}$.

(PLANTIN, C., «Analyse et critique du discours argumentatif» in KOREN, Roselyne e AMOSSY, Ruth (Org.), 2002, Après Perelman: quelles politiques pour les nouvelles rhétoriques?, Paris, L'Harmattan, p. 229).

${ }^{2}$ A demarcação de que se trata aqui é a que Plantin estabelece relativamente à teoria da «argumentação na língua» tal como a propuseram Jean-Claude Anscombre e Oswald Ducrot (cf. ANSCOMBRE, J-C., DUCROT, O., 1997, L'argumentation dans la langue, Bruxelles, Pierre Mardaga Editeur). À forma de abordar a argumentação por si proposta chama Plantin «modèle dialogal». Este renuncia «à voir dans l'argumentation quelque chose d'élémentaire, à tout sens du terme, et se propose de repenser l'activité argumentative dans un cadre élargi, où l'énonciation est située sur fond du dialogue» e onde a noção de «question argumentative» se torna central (Cf. PLANTIN, C., 2005, L'argumentation, Paris, P.U.F., p. 52).

3 «une forme de'interaction problématisante formée d'interventions orientées par une question» (PLANTIN, C., «Analyse et critique du discours argumentatif» in KOREN, Roselyne e AMOSSY, Ruth (Org.), 2002, Après Perelman: quelles politiques pour les nouvelles rhétoriques?, Paris, L'Harmattan, p. 230).

4 «une révision de ce qu'est fondamentalement une donnée en argumentation» (PLANTIN, C., 2005, L'argumentation, Paris, P.U.F., p. 73).

${ }^{5}$ Somos, desta forma, sensíveis às palavras de Plantin quanto este afirma que «les retours sur l'histoire d'une tradition de recherche incitent évidemment à des projections sur le présent e l'avenir. On peut penser que la priorité donnée aux objets complexes traités 
É esse o objectivo deste artigo, no qual procuro ir ao encontro da importância que Plantin atribui à necessidade de «destacar um conjunto sistemático de conceitos que permitam o estudo da argumentação no diálogo e no discurso» ${ }^{6}$.

De acordo com a definição citada, que fenómenos devem ser estudados pela teoria da argumentação?

Em primeiro lugar a argumentação não é monológica, mas interactiva. Mais concretamente, ela apresenta uma estrutura tripolar, no sentido em que remete para uma dinâmica que articula três instâncias: o pólo Questão (ou Terceiro), o pólo Proponente e o pólo Opositor. Estas três instâncias, mais do que desempenhos levados a cabo por pessoas concretas, devem ser consideradas em termos funcionais. Assinalam papéis de actuação necessários para a identificação de uma interacção como argumentação e qualquer deles pode ser ocupado, no decurso de uma argumentação, por qualquer dos intervenientes. Assim, nota Plantin:

«numa interacção concreta, o mesmo papel de actuação pode ser tomado por vários actores (falar-se-á, então, de aliança argumentativa). Os actuantes podem ocupar sucessivamente cada uma das posições argumentativas (ou papéis de actuação) segundo todos os trajectos possíveis» ${ }^{7}$.

Em segundo lugar - e é esse um dos aspectos que o torna fecundo - este modelo tripolar, ao mesmo tempo que se apresenta como estrutura

dans une perspective pluridisciplinaire - qui est le trait le plus caractéristique de la situation actuelle - offre certaines ouvertures. Quoi qu'il en soit, le destin de cette nouvelle recherche dépendra largement de la qualité des cursus qui y préparent. Quelle vision organise les enseignements théoriques de l'argumentation, en France, actuellement? Comment procède-t-on, au-delà des sessions 'express', qui tiennent parfois davantage de l'exposé de vulgarisation que de la formation systématique? Y a-t-il à ce niveau des éléments de consensus suffisants pour que puissent surgir une méthodologie et des questions de recherche historiquement et théoriquement informées, capables d'organiser cet intérêt commun pour l'argumentation qui se manifeste actuellement à travers toutes les disciplines? (Cf. PLANTIN, C., «Situation des études de l'argumentation: de délégitimations en réinventions» in DOURY, M. e MOIRAND, S. (Org.), 2004, L'argumentation aujourd'hui. Positions théoriques en confrontation, Paris, Presses Sorbonne Nouvelle, pp. 177-178).

6 «dégager un ensemble systématique de concepts permettant l'étude de l'argumentation dans le dialogue et dans le discours» (PLANTIN, C., 2005, L'argumentation, Paris, P.U.F., pp. 72-73).

7 «Dans une interaction concrète, le même rôle actanciel peut être tenu par plusieurs acteurs (on parlera alors d'alliance argumentative). Les acteurs peuvent occuper successivement chacune des positions argumentatives, selon tous les trajets possibles» (PLANTIN, C., 2005, L'argumentation, Paris, P.U.F., p. 65). 
de uma interacção argumentativa, é pensado de modo a evidenciar as características que o especificam como tal, a saber, a de se tratar, por um lado, de uma interacção problematizante e, por outro, de uma interacção polarizada num foco comum àqueles que interagem, ou seja, numa questão ${ }^{8}$. Escreve Plantin:

«Uma dada situação linguageira começa a tornar-se argumentativa quando se manifesta uma oposição de discursos. Dois monólogos justapostos, contraditórios, sem alusão um ao outro, constituem um díptico argumentativo. É sem dúvida a forma argumentativa de base: cada um repete a sua posição. A comunicação é plenamente argumentativa quando esta diferença é problematizada numa Questão e se destacam nitidamente os três papéis de actuação do Proponente, do Opositor e do Terceiro»9.

A partir do modelo tripolar e das características para que remete, duas considerações se podem destacar. Por um lado, trata-se de uma interacção disciplinada, disciplina esta que remete para a capacidade das intervenções se manterem na órbita de algo que deve permanecer comum para que a própria argumentação seja possível e se possa desenvolver. Por outro, esta dimensão comum, mais do que um consenso, representa uma esfera de relevância partilhada, algo que se constitui como um assunto em questão ${ }^{10}$,

8 «Le Tiers assure en particulier la stabilité de la question, et, de façon dérivée, juge ainsi la pertinence des argumentations. Il ne suffit pas de prouver, il faut encore que ce qui est prouvée soit en relation avec la question» (PLANTIN, C., 2005, L'argumentation, Paris, P.U.F., p. 64).

9 «Une situation langagière donnée commence ainsi à devenir argumentative losqu'il s'y manifeste une opposition de discours. Deux monologues juxtaposés, contradictoires, sans allusions l'un à l'autre, constituent un diptyque argumentatif. C'est, sans doute, la forme argumentative de base : chacun répète sa position. La communication est pleinement argumentative lorsque cette différence est problématisée en une Question, et qui se dégagent nettement les trois rôles de Proposant, d'Opposant et de Tiers» (PLANTIN, C., 2005, L'argumentation, Paris, P.U.F., p. 63. Subl. meu). Note-se que Plantin coloca, desta forma, a questão de saber o que é que torna uma interacção discursiva numa argumentação, ou seja, a questão do devir-argumentação do discurso.

${ }^{10}$ Como nota Jean Goodwin, se por um lado, «an issue is a less or more determinate object of contention that is, under circumstances, worth arguing about» por outro, «an issue arises when we make an issue of it» (Cf. GOODWIN, Jean, 2002, «Designing Issues» in EEMEREN, F. H. van e HOUTLOUSSER, P. (Eds), 2002, Dialectic and Rhetoric. The Warp and Woof Argumentation Analysis, Dordrecht, Kluwer Academic Publishers, p. 86). É também notória, nesta formulação, a preocupação com o processo de formação que converte uma troca verbal numa argumentação. 
de tal modo que quem interage se possa entender mesmo não estando de acordo. Como escreve Francis Jacques

«o diálogo não é forçosamente consensual, ele é também o lugar onde se vêem crescer os verdadeiros desacordos, mas não sem que nos consigamos entender sobre o próprio desacordo. (...) O ideal é que cada um possa formar a ideia de um acordo pelo menos possível sobre o qual se ergue o desacordo. É também a única forma de chegar a um verdadeiro dissentimento, que não repouse num malentendido. Aliás, o prazer do diálogo, que aos meus olhos é sem igual, é menos o do consenso do que o das fecundações incessantes e o da probidade no controlo mútuo do pensamento» ${ }^{11}$.

Ora, como vimos, esta ideia de entender-se sem estar de acordo, para além de remeter para um espaço comum - a que Plantin chama «questão» - remete também para a forma que caracteriza a interacção. Aqui, a palavra utilizada é «problematizante».

No entanto, sublinha ainda o autor, esta problematização não significa necessariamente conflitualidade e polémica. Poder-se-á dizer que ela é antes uma co-construção ${ }^{12}$ (desenvolvida de acordo com a estrutura tripolar anteriormente referida), no sentido em que vai fazendo surgir configurações e em que corresponde a uma conduta de ensaio aberta a concretizações possíveis ${ }^{13}$. A questão da conflitualidade e da polémica surge quando o confronto de perspectivas dá lugar a um confronto entre os participantes considerados como actores. Plantin distingue, como vimos, entre os participantes como actuantes (e, neste caso, as considerações que

11 «le dialogue n'est pas forcément consensuel, il est aussi le lieu où l'on voit grandir les vrais désaccords, mais non sans que l'on parvienne à s'entendre sur le désaccord même. (...) L'essentiel est que chacun puisse former l'idée d'un accord au moin possible sur lequel s'enlève le désaccord. C'est aussi la seule façon d'aboutir à un vrai dissentiment, qui ne repose pas sur un malentendu. D'ailleurs, le plaisir du dialogue, qui est sans égal à mes yeux, est mois celui du consensus que des fécondations incessantes et de la probité dans le contrôle mutuel de la pensée» (JACQUES, F., «Argumentation et stratégies discursives» in LAMPEREUR, A. (Ed.), 1991, L'argumentation, Mardaga, Liège, p. 165).

12 «Les conclusions ne sont admises ni au vu de la correction d'une inférence (argumentation logique) ni sous l'effet d'une persuasion (argumentation rhétorique), mais elles sont co-construites» (PLANTIN, C., 1998, «L'interaction argumentative» in Dialoganalyse VI, Tübingen, Max Verlag, p. 153).

13 Vai no mesmo sentido a afirmação de Willard quando fala do aparecimento dos argumentos: «arguments, then, are 'emergent'. We make them up as we go along» (WILLARD, C. A., 1989, A Theory of Argumentation, Tuscaloosa/London, The University of Alabama Press, p. 67). 
configuram as suas perspectivas são aquilo que conta, podendo certas iniciativas corresponder ao papel de Proponente, outras ao papel de Opositor e outras, ainda, ao papel de Questionador que coloca em dúvida) e os participantes como actores, ou seja, como pessoas concretas cujo ethos ou imagem de si é posto em causa pelo próprio desenrolar da interacção (sendo este um ponto em que a argumentação cruza a retórica). Assim, escreve:

«Importa, com efeito, não confundir a oposição entre discursos — entre actuantes - e as eventuais colaborações ou conflitos entre pessoas - entre actores. A situação argumentativa, tal como a definimos, só é conflitual quando os argumentadores se identificam com os papéis argumentativos. (...) Por razões teóricas e empíricas, a polemicidade não é, por conseguinte, inerente à argumentação. Ao que parece, ela chega fatalmente quando, tendo-se os actores estabilizado nas posições dos actuantes, os discursos desempenham um papel essencial na estruturação das pessoas dos argumentadores» ${ }^{14}$.

Esta afirmação reforça a ideia que acima expressámos segundo a qual a argumentação é uma conduta de ensaio que tem por função a concretização do possível. Confrontar ideias não é necessariamente confrontar posições pessoais. Pode ser, pura e simplesmente, habitar esse espaço suspenso $^{15}$ ou ainda não estabilizado em que procuramos assentar ideias

14 «Il importe en effet de ne pas confondre l'opposition entre discours — entre actants - et les éventuelles collaborations ou conflits entre personnes — entre acteurs. La situation de l'argumentation telle qu'elle vient d'être définie n'est conflictuelle que lorsque les acteurs s'identifient aux rôles argumentatifs. (...) Par des raisons théoriques et empiriques, la polémicité n'est donc pas inhérente à l'argumentation. Elle survient fatalement, semble-t-il, lorsque les acteurs étant stabilisés sur les positions d'actants, les discours jouent un rôle essentiel dans la structuration des personnes des argumentateurs» (PLANTIN, C., «Analyse et critique du discours argumentatif» in KOREN, Roselyne e AMOSSY, Ruth (Org.), 2002, Après Perelman: quelles politiques pour les nouvelles rhétoriques?, Paris, L'Harmattan, p. 231).

15 É assim que Ruth Amossy, na esteira de Jean-Blaise Grize, engloba na sua definição de argumentação a possibilidade desta visar apenas a reflexão. Eis a sua definição de argumentação: «les moyens verbaux qu'une instance de locution met en œuvre pour agir sur ses allocutaires en tentant de les faire adhérer a une thèse, de modifier ou de renforcer les représentations et les opinions qu'elle leur prête, ou simplement de susciter leur réflexion sur un problème donné» (AMOSSY, Ruth, 2006, L'argumentation dans le discours, Paris, Armand Colin, p. 37). Neste sentido a definição de argumentação afasta-se da necessidade de a ligar a uma finalidade resolutiva que visa poder decidir de que lado está a razão. 
que procuramos para assuntos em questão num contexto pragmático que emerge das próprias estratégias discursivas que vão moldando a interacção ${ }^{16}$.

Neste sentido, mais do que remeter as interacções para posições pessoais, há que partir das instruções que as configuram como uma perspectiva impessoalmente considerada ${ }^{17}$. Porque, independentemente da autoria da iniciativa discursiva, podemos configurar a perspectiva para que ela remete. (Assim, sem ter de referir os nomes dos seus subscritores, podemos dizer que sobre um determinado assunto em questão há duas perspectivas, uma que propõe $X$ e outra que se opõe a $X$ ou que se contrapõe a X propondo Y. Para dar um exemplo, no mais recente referendo sobre a legalização da interrupção voluntária da gravidez ocorrido em Portugal, as duas perspectivas em jogo eram a do SIM e a do NÃO).

16 Sobre a noção de «estratégia discursiva» escreve Jacques: «J'appelle 'stratégie discursive' une séquence d'interactions communicatives en tant qu'elles construisent peu à peu leur contexte pragmatique» (JACQUES, F., «Argumentation et stratégies discursives» in LAMPEREUR, A. (Ed.), 1991, L'argumentation, Mardaga, Liège, p. 156). De acordo com esta ideia, a dimensão resolutiva de uma argumentação pode constituir-se como um dos seus contextos pragmáticos possíveis, mas não tem de ser colocada, como por exemplo acontece na pragma-dialéctica, como $a$ finalidade da argumentação. Por outro lado, numa argumentação, dos seus contextos pragmáticos fazem também parte as situações específicas em que esta pode ocorrer. É assim que uma argumentação desenvolvida num tribunal está condicionada quer pelo carácter institucional das regras que a regulam, quer pela finalidade resolutiva em que é enquadrada quer, ainda, pelas consequências pessoais que resultam das decisões aí tomadas. Ainda que o modelo jurisprudencial tenha servido de inspiração àqueles que delimitaram o campo da argumentação (Perelman e Toulmin), em nosso entender ele revela-se demasiado restrito para uma teorização abrangente da argumentação. Na realidade, a argumentação engloba problemas mais latos do que os da decisão conforme regras institucionais que visam determinar de que lado está a razão, sendo, na sua generalidade máxima, uma forma interactiva de tematizar assuntos em questão. Assim, por exemplo, procurar mostrar a alguém o sentido de uma determinada perspectiva, não tendo de originar uma decisão ou uma resolução, não deixa de convocar uma interacção argumentativa.

${ }^{17} \mathrm{E}$, neste sentido, o discurso, linguisticamente considerado, fornece determinadas instruções para aceder a esse nível impessoal. Assim, por exemplo, o uso de um «mas», ou de um «logo» (a que os teorizadores da argumentação da língua chamam «marcadores» ou «operadores» argumentativos) fornece indicações do sentido do discurso independentemente de quem o proferiu. Interpretamos a partir desta distinção entre o plano impessoal e o plano pessoal a diferença radical que Ducrot propõe entre a argumentação linguística e a argumentação retórica (cf. DUCROT, O., «Argumentation rhétorique et argumentation linguistique» in DOURY, M. e MOIRAND, S. (Org), L'argumentation aujourd'hui. Positions théoriques en confrontation, Paris, Presses Sorbonne Nouvelle). 
Aliás, construir uma perspectiva não significa, sequer, subscrevê-la, mas tão apenas perceber a sua configuração ${ }^{18}$. É aliás por isso que podemos fazer o esforço de suspender a nossa própria perspectiva e colocarmo-nos numa perspectiva que não é a nossa ou, como coloquialmente se costuma dizer, ver a questão de vários prismas, ouvir o outro lado.

Mas voltemos à definição de Plantin. De acordo com ela o estudo da argumentação poderá ter como base descritiva a resposta às seguintes perguntas:

A1. Que questão orienta as intervenções dos participantes? Em que esfera de relevância problemática se polarizam os discursos? Relativamente a quê podemos classificar as intervenções como «pró» ou como «contra»?

B1. Que características específicas diferenciam as tematizações dos intervenientes? Como, e em que pontos, é que as intervenções configuram perspectivas diferentes? (Revelando-se aqui a diferença como a dimensão de problematização).

C1. Para que respostas orientam essas tematizações (sentido) e que tipo de inferências as sustentam (raciocínio)?

No entanto, talvez seja possível melhorar estas perguntas. Um dos pontos em que tal poderá ser feito é o que coloca uma questão como pólo de uma argumentação. Sabemos que, na sua abordagem problematológica da argumentação, Michel Meyer propõe nunca perder de vista que uma resposta é sempre resposta a uma questão. Foi aliás partindo desta ideia que Grize chegou a descrever o processo de uma argumentação (que não procede do verdadeiro para o verdadeiro, mas que anda de questão em questão) da seguinte forma:

«a) Ponto de partida: uma descrição daquilo de que se trata.

b) Por desnivelamentos sucessivos, respostas a questões abertas, logo delimitação do campo de que se trata.

c) Respostas a questões fechadas.

d) Conclusão que decorre: a resposta que permanece» ${ }^{19}$.

${ }^{18}$ Grize distingue, a este respeito, entre «receber», «aceitar»e «aderir», remetendo cada uma destas operações para a satisfação de condições específicas (cf. GRIZE, J.-B., 1997, Logique et langage, Paris, Ed. Ophrys, p. 73).

19 «a) Point de départ: une description de ce don't il s'agit.

b) Par dénivellations sucessives, réponses à des questions ouvertes, donc délimitation du champ de ce don't il s'agit. 
Mais tarde, todavia, reconheceu dificuldades nesta ideia de remeter a argumentação para uma questão. Assim, escreveu:

«A ideia [de Michel Meyer] é a de que todo o enunciado é resposta a uma questão. Sendo assim, dar-lhe sentido 'consiste em questionar uma resposta enquanto tal' (Meyer, 1986, p. 242). (...) Mas é claro que aquilo que mais frequentemente acontece, e assim que nos encontramos perante uma esquematização completa, é que o número de questões para as quais é possível encontrar uma resposta é ilimitado» ${ }^{20}$.

Ou seja, a unidade de leitura «questão» pode funcionar para enunciados e para a sua argumentatividade, mas uma argumentação - que Grize entende ser indissociável de uma «esquematização» - envolve uma complexidade que não se deixa abordar pelo par questão-resposta ${ }^{21}$.

O problema com que somos então confrontados é o de saber que unidade de leitura pode ser adequada para que, mais do que a argumentatividade dos enunciados ou os pequenos procedimentos argumentativos por eles veiculados, possamos descrever uma argumentação. E é face a este problema que me parece adequado introduzir a ideia de «assunto em questão» como unidade de leitura e análise das argumentações.

Direi que o «assunto em questão» é o pólo semiótico da argumentação, o que se revela como a esfera de relevância de que tira sentido a argumentatividade dos enunciados no plano macro ou superstrutural, de que nos fala van Dijk. Escreve este autor:

«É contudo estranho que mesmo hoje em dia haja gramáticas do discurso que operem apenas no nível 'linear' das frases ou proposições subsequentes e

c) Réponses à des questions fermées.

d) Conclusion qui se détache: la réponse qui reste» (GRIZE, J.-B., «Raisonner en parlant» in, MEYER, M. (Ed.), 1986, De la métaphysique à la rhétorique, Bruxelles, Éditions de l'Université de Bruxelles, p. 54).

20 «L'idée [de Michel Meyer] en est que tout énoncé est réponse à une question, Dès lors lui donner un sens 'consiste à questionner une réponse en tant que telle' (Meyer, 1986, p. 242). (...) Mais il est clair que le plus souvent, et lorsqu'on est en présence d'une schématisation tout entière, le nombre des questions auxquelles il est possible d'y avoir une réponse est illimité» (GRIZE, J.-B., 1996, Logique naturelle \& communications, Paris, P.U.F., p. 118).

${ }^{21}$ Vão também no sentido da insuficiência deste par as palavras de Moisés de Lemos Martins quando afirma que «talvez haja que contrapor a Meyer que a plenitude da comunicação não se confunde com o par questão/resposta, mas que, pelo contrário, se trata de um fenómeno de intricação semântica muito mais íntima» (MARTINS, Moisés de Lemos, 2002, Semiótica em http://hdl.handle.net/1822/996, p. 102). 
ignorem as estruturas globais cruciais (macroestruturas, superstruturas) que definem o sentido e a forma dos textos no seu conjunto» ${ }^{22}$.

E explica, numa outra obra:

«Uma característica essencial do discurso consiste no facto de ser, não só local, mas globalmente coerente. Para além das relações de significado entre as frases subsequentes, o texto tem também uma unidade semântica global. Esta coerência global é descrita por aquilo que nós todos intuitivamente conhecemos como temas ou tópicos. Os tópicos sumariam conceptualmente o texto e especificam a sua informação mais importante. Em termos teóricos, esses tópicos podem ser descritos como macroproposições semânticas, isto é, como proposições derivadas de sequências de proposições no texto: por exemplo, através de macro-regras como a selecção, a abstracção e outras operações que reduzem a informação complexa. O conjunto hierárquico de tópicos ou macroproposições forma a estrutura temática ou de tópicos do texto. Os utentes da linguagem empregam essas macroestruturas para perceber globalmente e sumariar o texto» ${ }^{23}$.

Voltando agora ao nosso problema, diremos que uma argumentação se caracteriza por apresentar uma «estrutura temática» que possibilita proceder a sínteses. Faz parte da estrutura temática de uma argumentação apontar para uma esfera de relevância que podemos identificar sinteticamente como o «assunto em questão». Aliás, caso isso não seja possível, dificilmente se poderá considerar que um conjunto de interacções verbais seja uma argumentação. Poderemos assinalar a argumentatividade intrínseca de enunciados, mas não saberíamos dizer qual é o seu fio condutor e, sem isso, pouco mais além poderíamos ir do que constatarmos que estamos em presença de um amontoado avulso de interacções comunicativas, eventualmente esquematizáveis e analisáveis, mas incapazes de se inserirem na coesão global de que tiram o seu sentido $\operatorname{argumentativo~}^{24}$.

22 «It is therefore strange that even today there are discourse grammars that only operate at the 'linear' level of subsequent sentences or propositions, and ignore the crucial global structures (macrostructures, superstructures) that define the overall meaning and form of texts» (DIJK, Teun A. van, 2004, From text grammar to critical discourse analysis in http://www.discourses.org/OldArticles/From\%20text\%20grammar\%20to\%20critical $\%$ 20discourse\%20analysis.pdf).

${ }^{23}$ DIJK, Teun A. van, 2005, Discurso, Notícia e Ideologia. Estudos na Análise Crítica do Discurso, Porto, Campo das Letras, p. 65.

${ }^{24}$ Segundo van Dijk um dos conceitos fundamentais da análise semântica do discurso é o de «coerência». Como é que o sentido das proposições se conjugam no discurso? A esta 
É também van Dijk quem refere que o discurso possuiu dois níveis de coerência:

a) o nível local, que tem a ver com a maneira como se relacionam as proposições subsequentes de um discurso, quer de um ponto de vista referencial (ou seja, a selecção de factos e a sua articulação através de vários tipos de relação: consequência, causa, tempo, condição, etc.), quer do ponto de vista funcional (ou seja, a forma como se organiza a progressão discursiva, fazendo funcionar certas proposições como condição de outras, criando assim uma estrutura hierárquica que, segundo o modelo tradicional, articula proposições com a função de premissa e proposições com a função de conclusão).

b) o nível global que já não tem a ver com as microproposições mas sim com as macroproposições, ou seja, com a unidade semântica do discurso como um todo.

Neste sentido, uma das exigências de tomar um discurso como argumentação é a da coerência global poder ser percebida e enunciada através de uma interrogação que aceda ao que tematicamente está em questão e, simultaneamente, permita compreender a coerência local das operações que funcionam no interior da estrutura global.

Sendo assim poderíamos reformular a pergunta A1 e dizer que faz parte da descrição de uma argumentação a tarefa A2, ou seja:

A2. A identificação do assunto em questão sob a forma de uma macroproposição genérica interrogativa (coerência global, pólo problemático aglutinador).

Mas não será que uma tal síntese é arbitrária? Segundo Grize um discurso contém instruções na medida em que

«uma esquematização aparece assim não tanto como a expressão discursiva de um sentido que como uma solicitação a construir um sentido. (...) uma esquematização dada não autoriza uma qualquer interpretação. Os seus sentidos possíveis são limitados pela significação de cada um dos termos, ao

\footnotetext{
pergunta responde o seguinte: «We may study such coherent relations for sentences that immediately follow each other (the micro level of analysis) but also for the meaning of discourse as a whole (macro level of analysis). In both cases we in fact are explaining what makes discourse meaningful, and how a discourse is different from an arbitrary (incoherent) set of sentences» (DIJK, Teun A. van, «The Study of Discourse» in DIJK, Teun A. van (Ed.), 1997, Discourse Studies. A Multidisciplinary Introduction. Vol. 1: Discourse as structure and process, London, Sage Publications, p. 9).
} 
mesmo tempo que eles são conduzidos por cotextos, ou seja, por aquilo que precede cada enunciado e por aquilo que se lhe segue» 25 .

Numa argumentação, as formações discursivas surgem assim como meios de instruir o assunto em questão. Aliás, na definição que Plantin propõe, esta ideia de que uma argumentação é algo que se vai formando pelas diversas intervenções está bem patente. É aliás esta transitividade que torna muitas vezes complicado o «congelamento» do discurso em proposições dele retiradas para fins analíticos, a que nos referiremos adiante.

Chamo tematização à instrução de um assunto em questão ${ }^{26}$. Tematizar, mais do que encadear proposições, é configurar um assunto pela atribuição selectiva da relevância concedida aos recursos que o desenham como perspectiva.

A ideia de assunto em questão parece, com efeito, como susceptível de ser abordada analiticamente através da metáfora do desenho ${ }^{27}$, constituindo-se esta como um modo apropriado de descrever os procedimentos de tematização. Assim, os considerandos que cada parte apresenta e evoca - as questões que selecciona, os dados a que recorre, as relações que entre eles estabelece (quer por associações, quer por dissociações), o peso ou importância relativa que lhes confere, o modo como os liga a uma eventual resposta ou conclusão, etc. - são os elementos temáticos que configuram uma perspectiva específica.

De notar, ainda, que a própria noção de perspectiva - e mais precisamente a ideia de que qualquer tematização é solidária de uma determinada forma de abordar um assunto em questão ${ }^{28}$ - tem uma

25 «Une schématisation apparaît ainsi non tellement comme l'expression discursive d'un sens que comme une sollicitation à construire un sens. (...) Une schématisation donnée n'autorise pas n'importe quelle interprétation. Ses sens possibles sont limités par la signification de chacun de ses termes, en même temps qu'il son conduits par les cotextes, soit ce qui précède et ce qui suit chaque énoncé» (GRIZE, J.-B., 1996, Logique naturelle \& communications, Paris, P.U.F., p. 118).

26 Escreve Plantin: «Les interactions fortement argumentatives reposent sur un différend qui présente des caractéristiques spécifiques: (...) il est thématisé dans l'interaction» (PLANTIN, C., 2005, L'argumentation, Paris, P.U.F., p. 56).

${ }^{27}$ Essa é uma abordagem proposta por Jean Goodwin, nomeadamente em GOODWIN, Jean, 2007, «Argument Has No Function» in Informal Logic, vol. 27, n. ${ }^{\circ}$ 1, pp. 69-90.

${ }^{28}$ É neste sentido que Willard observa, a propósito da argumentação, que «the highest-order construct for epistemic purposes is 'communication' and its subordinate notion is 'perspectivity'»(WILLARD, C. A., 1983, Argumentation and the Social Grounds of Knowledge, Alabama, The University of Alabama Press, p. 4). 
correspondência directa com o que Plantin refere como a dimensão «problematizante» da interacção argumentativa. A dimensão problematizante de uma perspectiva reside no facto de ela não ser única. É uma possibilidade de considerar um assunto em questão a partir de certas considerações e define-se pela sua diferença relativamente a outros modos possíveis de o considerar. A uma perspectiva corresponde um modo de configurar um assunto em questão que se demarca de outros modos de o fazer.

Poderíamos dizer que todo o trabalho de configurar uma perspectiva sobre um assunto em questão remete para uma das partes fundamentais da retórica, a saber, a inventio, ou seja, a descoberta ou selecção das considerações e dos recursos que funcionarão como base do discurso ${ }^{29}$. Repare-se que, aqui, a base é, antes de mais, uma base temática e não uma questão de raciocínio (o entimema aristotélico). Trata-se do sensus e não da ratio. Mesmo que esses considerandos possam servir de ponto de partida para raciocínios - e é nesse sentido que também em argumentação se fala vulgarmente de premissas - é neles que se joga a questão do sentido (do desenho do assunto, da orientação que o configura como perspectiva) - e é sempre do sentido prévio que preside às selecções com que se tematiza o assunto que os raciocínios, mais do que uma força lógica, retiram a sua força de impacto, seja esta persuasiva, dissuasiva ou, simplesmente, mobilizadora da atenção do interlocutor, que é também uma forma não negligenciável - como, aliás, devidamente assinalam aqueles que partem de uma perspectiva retórica da argumentação - de lhe conferir relevância ${ }^{30}$.

${ }^{29}$ A questão, aqui, é: se quero pronunciar-me sobre um assunto em questão, com que recursos organizarei o meu discurso? É óbvio que, neste ponto, a formação académica e cultural, as competências intelectuais, os níveis de informação de que se dispõe, as capacidades oratórias e muitos outros factores são essenciais na concretização desta tarefa, o que mostra bem que a competência argumentativa nunca se pode reduzir a uma questão de competência técnica especializada.

${ }^{30}$ Do ponto de vista da semântica do discurso é também interessante referir que alguns teóricos consideram como fundamental numa interacção verbal o controlo de quatro tipos de organização da informação; a organização retórica, a organização referencial, a organização temática e a organização da atenção. A primeira diz respeito às finalidades do discurso e é importante na medida em que constrange a produção do conteúdo proposicional do discurso e a interpretação de quem o recebe; a segunda diz respeito aos interlocutores, àquilo que lhes é comum na interacção, e é importante para saberem do que estão a tratar; a terceira remete para o que é nuclear e periférico e é essencial para o fio condutor da interacção; a quarta diz respeito à atenção e é importante para situar os passos que se dão no contexto devido (cf. TOMLIN, Russell S., FORREST, Linda, PU, Ming Ming 
Assim postas as coisas, podemos agora reformular, também, os pontos B1 e C1, apresentando-os de acordo com as seguintes tarefas descritivas:

B2. Inventariação dos tópicos tematizadores do assunto em questão (o conjunto de considerandos trazidos ao discurso de forma a configurarem o assunto, ou modo de o perspectivar a nível da informação genérica) e inventariação das informações específicas (que funcionam como premissas ou argumentos para a articulação de raciocínios no interior da perspectiva e que visam o estabelecimento de conclusões).

C2. Identificação da(s) resposta(s) proposta(s) que especifica(m) uma posição a partir da perspectiva sobre o assunto em questão, dos considerandos evocados, da fixação de premissas e dos raciocínios desenvolvidos a partir delas.

Retomando agora a definição de argumentação proposta por Plantin, (relembro: «uma forma de interacção problematizante formada por intervenções orientadas por uma questão») poder-se-á, após o conjunto de reflexões que apresentei, retirar um novo léxico que parece apropriado para a análise do discurso enquanto argumentação, a saber:

- assuntos em questão (o pólo semiótico de uma argumentação);

- perspectivas (vias diferenciadas que configuram um modo de abordar o assunto em questão);

- tematização (processo selectivo de recursos através do qual a perspectiva é desenhada e estabelece pontos que podem servir de premissas a raciocínios);

- respostas (orientações conclusivas para que tende o sentido da tematização ou asserção conclusiva em que a questão do sentido assume a forma de uma questão de raciocínio).

$\mathrm{Na}$ minha perspectiva este léxico de análise tem a virtude de não separar a dimensão semiótica do pensamento (produção de sentido nas interacções comunicativas em que está em causa perspectivar assuntos em questão) dos termos em que se poderá proceder, de um ponto de vista prático, à sua avaliação. São ferramentas conceptuais que, permitindo clarificar a dinâmica argumentativa, apresentam, por isso

\footnotetext{
e KIM, Myung Hee «Discours Semantics», in DIJK, Teun van (Ed.), 1997, Discourse as structure and process, Sage Publications, pp. 66 e seguintes). Para estes autores há também três níveis de coerência em que se podem situar as interacções discursivas: o da coerência global, o da coerência episódica e o da coerência local.
} 
mesmo, uma mais valia crítica, tal como Ruth Amossy sublinha ao afirmar que

«a abordagem descritiva, não menos que a normativa, pretende ser um contributo para a crítica das trocas verbais consideradas na sua dimensão de interacção social. (...) a análise argumentativa apoia-se na ideia de que a aclaração de um funcionamento discursivo é também uma elucidação, se não um desvelamento, da forma como ele tenta agir sobre o parceiro. Dito de outra forma, a análise seria ela mesma uma ferramenta crítica» ${ }^{31}$.

No que diz respeito à questão da avaliação das argumentações, a posição de Plantin é lucidamente prudente. Destaca dois tipos de perguntas críticas, a saber:

1. «Será que o analista linguístico e argumentativo pode mostrar que um discurso em língua natural é falacioso?» ${ }^{32}$

2. «Será que se pode, pela análise argumentativa, mostrar que um discurso — por exemplo, um discurso sexista, racista... - é um mau discurso (falso, manipulador...)?» ${ }^{33}$

À primeira pergunta Plantin responde com uma afirmatividade reticente.

Por um lado, uma falácia remete sempre para uma abordagem lógica do discurso, para o estudo das inferências que aí são postas a funcionar. Ora, se entendermos que as inferências implicam regras lógicas, a violação

31 «l'approche descriptive, non moins que l'approche normative, se veut une contribution à la critique de l'échanges verbaux prises dans leurs dimension d'interaction sociale. (...) l'analyse argumentative s'appuie sur l'idée que la mise à plat d'un fonctionnement discursif est aussi une mise au jour, sinon un dévoilement, de la façon dont il tente d'agir sur le partenaire. En d'autres termes, l'analyse serait en elle-même un outil critique» (AMOSSY, Ruth, 2006, L'argumentation dans le discours, Paris, Armand Colin, p. 19).

32 «Peut-on, par l'analyse linguistique et argumentative, montrer qu'un discours en langue naturelle est un discours fallacieux?» (PLANTIN, C., «Analyse et critique du discours argumentatif» in KOREN, Roselyne e AMOSSY, Ruth (Org.), 2002, Après Perelman: quelles politiques pour les nouvelles rhétoriques?, Paris, L'Harmattan, p. 232).

33 «Peut-on, par l'analyse argumentative montrer qu'un discours — par exemple un discours sexiste, raciste... - est un mauvais discours (faux, manipulatoire...)?» (PLANTIN, C., «Analyse et critique du discours argumentative» in KOREN, Roselyne e AMOSSY, Ruth (Org.), 2002, Après Perelman: quelles politiques pour les nouvelles rhétoriques?, L'Harmattan, p. 237). 
de tais regras pode conduzir a invalidar uma conclusão e a rejeitar o raciocínio com que se pretende chegar a uma resposta para um assunto em questão. No entanto - e essas são as reticências de Plantin - a abordagem lógico-epistémica obriga a traduzir o texto em relações inferenciais com base numa teoria do argumento que vê neste uma articulação entre premissas e conclusão (e esta «tradução lógica» que se concentra no plano proposicional do discurso é, desde logo, uma redução que levanta dificuldades e problemas, sendo fácil de recusar: «Mas não é isso que eu estou a dizer...»). Se, contudo, uma destas articulações mina a lógica do texto, então ela é suficiente para o podermos classificar como falacioso ${ }^{34}$. Acontece que a lógica de um texto não se esgota no seu tecido lógico-inferencial e as deficiências que neste campo possamos encontrar podem não comprometer a perspectiva para que procuram orientar. Ou seja, para resumir, se os erros lógicos conduzem a conclusões falaciosas - e ao nível das questões de raciocínio a detecção de erros lógicos revela-se fundamental - nem por isso a existência de conclusões falaciosas têm necessariamente de invalidar uma argumentação considerada no nível das perspectivas e das configurações temáticas ${ }^{35}$.

No que diz respeito à segunda pergunta, Plantin é peremptoriamente negativo. E a sua ideia é simples: nesse caso, o analista deixaria de o ser e passaria a ser um argumentador.

Neste sentido, parece-me que Plantin subscreveria a ideia de Willard segundo a qual a única fonte legítima para falar de falácias é o nível dos raciocínios logicamente considerados e não ideologicamente avaliados, ou seja:

«Advogarei que os estudiosos da Argumentação usam falácia como um termo estrito da arte cuja fonte de autoridade é a lógica e não um termo abarcante para qualquer condenação que os críticos possam querer fazer. Esta tese não deriva da preferência de uma visão restrita sobre uma visão alargada (argumentarei adiante que os recentes modelos das falácias são apenas aparentemente alargadas), mas da convicção de que falácia é uma classificação inapropriada para defeitos morais, processuais e relacionais. Estes

${ }^{34}$ É, por exemplo, o caso de um famoso texto de Hitler no qual, partindo da ideia de que na natureza as espécies não se misturam, procura concluir que é da ordem da natureza as raças também não se misturarem (cf. Hitler, Mein Kampf, vol.1, cap. 11 (Nation and race) in http://www.hitler.org/writings/Mein_Kampf/).

35 É nesse sentido que na avaliação de um exercício de matemática certos erros podem não significar uma deficiência no modo de raciocinar. 
defeitos podem ser condenáveis, mas a classificação falácia não identifica a autoridade que está por detrás dessas condenações» ${ }^{36}$.

O léxico de análise a que atrás aludi, e que visa justamente fornecer novas ferramentas conceptuais que permitam descrever a interacção argumentativa, afigura-se apropriado para compreender e clarificar a dinâmica do desenho dos assuntos na interacção argumentativa e mostrar que uma argumentação não se pode reduzir a questões de raciocínio ou, se se preferir, que o nível dos raciocínios tira o seu sentido das perspectivas em que se inserem. Todavia, os raciocínios, se perspectivados de um ponto de vista lógico, ou seja, tendo em consideração a forma como inferem, podem afectar uma argumentação se, ao revelarem-se como falaciosos, puserem em causa a coerência global da perspectiva. Mas, também aí, a identificação do assunto em questão, que propusemos neste artigo como unidade de leitura das argumentações, é aquilo que pode seleccionar quais os raciocínios relevantes de acordo com o que está em causa numa determinada argumentação. É certo que um dos níveis de interacção com uma argumentação é focalizarmo-nos nas questões de raciocínio $^{37}$. E, nesse sentido, a capacidade de fazer inferências apropriadas revela-se como uma competência importante ${ }^{38}$. Mas, como defendemos mais atrás, uma argumentação é, acima de tudo, uma forma disciplinada e crítica de ler e interagir com os discursos ${ }^{39}$, atentando nos

36 «I advocate that Argumentation scholars use fallacy as a narrow term of art whose source of authority is logic and not as an all-encompassing term for every condemnation critics might wish to make. This claim does not stem from a preference for narrow versus broad definitions (I argue bellow that recent fallacy models are only apparently broad) but from the belief that fallacy is an appropriate label for moral, procedural, and relational defects. This flaws may be condemnable, but fallacy label misstates the authority behind such condemnations» (WILLARD, C. A., 1989, A Theory of Argumentation, Tuscaloosa/ London, The University of Alabama Press, p. 220).

${ }^{37}$ É aliás para este estreitamento que contribuem as normas institucionalizadas em que o que está em questão não é discutir mas aplicar regras, ou seja, ver o que é que se aplica a cada caso específico. Mas, ainda assim, se a própria aplicação de regras permite aproximar os processos argumentativos a finalidades resolutivas «racionais», nem por isso uma tal aplicação se limita a uma mecânica do raciocínio.

${ }^{38}$ É para esta orientação que aponta a perspectiva da chamada «lógica informal», tal como ela é desenvolvida, nomeadamente, nos trabalhos de Johnson e Blair (cf. JOHNSON, R.H. \& BLAIR, J. A., 2005, J.A., Logical Self-Defense, NY, IDEBATE PRESS).

${ }^{39}$ É preciso, contudo, considerar o discurso no âmbito mais lato da comunicação, nele incluindo quer aspectos verbais, quer aspectos paraverbais. Esta é uma posição defendida por Willard quando afirma que «arguers, like all communicators, use any or all of the 
movimentos metadiscursivos ${ }^{40}$ inerentes ao desenho dos assuntos (tematizações), destacando as perspectivas para que esse desenho aponta e avaliando os raciocínios com que eventualmente se procuram trazer respostas conclusivas para os assuntos em questão.

Ensaiando agora a sempre difícil transposição da estrutura das argumentações para uma forma diagramática, poderíamos representá-la da seguinte forma:

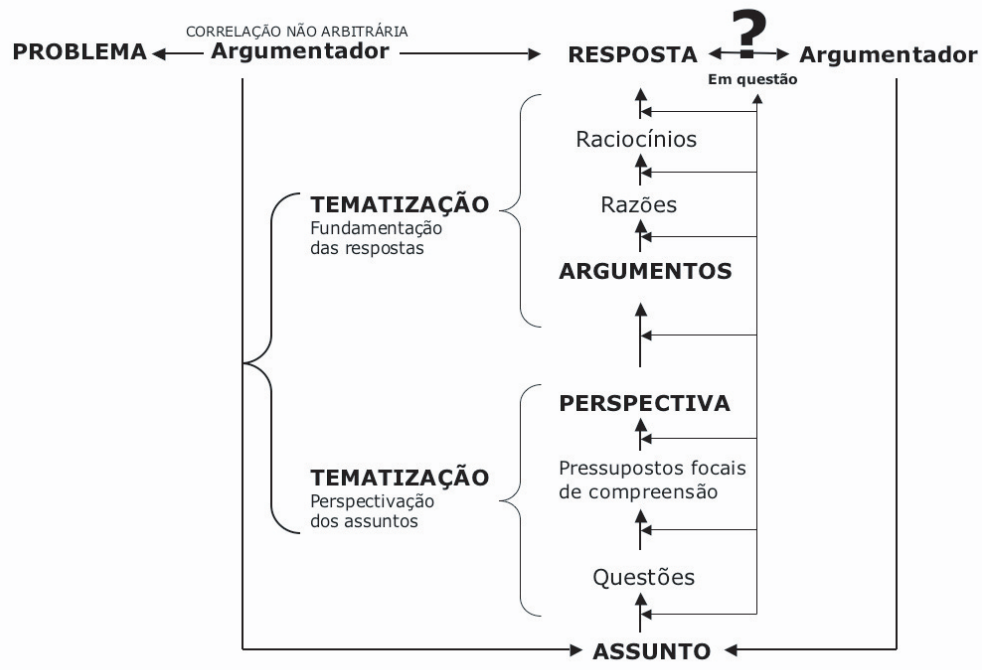

Esquema 1 - A estrutura das argumentações

communication vehicles available to them: serial predication, claiming, and reasoning-giving, as well as proxemic, paralinguistic, gestural, and facial clues. Once we have an argument anything used to communicate within it is germane to an analysis of how the argument proceeds and how it affects the arguers. (...) My answer is a package deal: any of the symbolic activities going on in an argument may affect its progress and outcomes» (WILLARD, C. A., 1989, A Theory of Argumentation, Tuscaloosa/London, The University of Alabama Press, p. 92). Plantin refere-se também a este aspecto inventariando um conjunto de procedimentos paraverbais característicos da manifestação de uma dissensão no decorrer de uma conversação (tentativa de tomar a palavra e recusa do outro lha ceder, aparecimento de cruzamentos entre turnos de palavra, aceleração do débito, etc.) (Cf. PLANTIN, C., 2005, L'argumentation, Paris, P.U.F., p. 56).

${ }^{40}$ Sobre a metadiscursividade, escreveram RISSO e JUBRAN que «a propriedade básica particularizadora da metadiscursividade é a da auto-reflexividade do discurso: este elabora-se focalizando-se a si mesmo, pela conjunção do que é dito com o acto de dizer. Por reportar o discurso ao acto de enunciação que o cria, auto-referenciando-se, o metadiscurso constitui-se simultaneamente como discurso e como glosa sobre o discurso» 
Explicitemos os elementos que nele encontramos:

1. A articulação não arbitrária entre um problema e uma resposta susceptível de desafio por outro argumentador é o âmbito mais geral e abstracto que define o estatuto do «argumentador». O desafio efectivo dessa resposta é o que opera o trânsito da argumentatividade para a focalização do discurso como argumentação. Por considerarmos que uma argumentação implica a permutabilidade da iniciativa argumentativa preferimos, em vez de utilizarmos as habituais dicotomias orador/auditório, emissor/receptor, locutor/ alocutário, etc., considerar uma argumentação como algo que ocorre de argumentador para argumentador.

2. A primeira especificação argumentativa de um problema implica que o assunto seja delimitado e uma tal circunscrição implica organizá-lo a partir da selecção de questões que são tidas como relevantes.

3. As questões de partida nunca são puras questões, mas implicam desde logo pressupostos focais de compreensão (pré-compreensão), o que equivale a dizer que elas propõem uma abordagem do assunto a partir de uma determinada perspectiva. É sempre no quadro de uma determinada perspectiva e do seu progressivo estreitamento que a resposta ao problema surgirá.

4. Sendo a resposta apresentada passível de ser questionada por aquele a quem é proposta, o assunto é abordado sob o modo do «em questão» e a tematização procurará organizar o discurso de modo a que a resposta possa ser aprovada.

5. A tematização implicará assim a apresentação de argumentos que invocam razões e permitem articular raciocínios. Neste nível de tematização, e se a perspectiva não for questionada, o estreitamento do assunto em questão tende a progredir de forma a fazer passar a resposta como uma questão de raciocínio.

\footnotetext{
(RISSO, Mercedes Sanfelice e JUBRAN, Clélia Cândida A. Spinardi, 1988, Self-reflexive discourse: Metadiscoursive processing of the text. DELTA. [online]. 1998, vol. 14, no. spe [cited 2007-07-19]. Available from: http://www.scielo.br/scielo.php?script=sci_arttext\&pid= S0102-44501998000300015\&lng=en\&nrm=iso >. ISSN 0102-4450.). Neste plano são importantes os prefaciadores metadiscursivos (como por exemplo: «Tomaremos agora em consideração», os recursos tematizadores (como por exemplo: «No que diz respeito a») e os demarcadores perspectivos (como por exemplo: «com isto oponho-me a»), não só no desenho dos assuntos como na explicitação de uma posição relativamente a um assunto em questão.
} 
A partir deste esquema, aquilo que é questionável numa argumentação, podendo originar um contra-discurso, são:

1. As questões com que se focaliza ou perspectiva o problema como assunto.

2. A perspectiva a partir da qual se pretende trazer uma resposta para o problema.

3. Os argumentos evocados para sustentar a resposta, isto é, a validação da sua relevância como razões.

4. A validade dos raciocínios que procuram apresentar a resposta como uma consequência (quase) lógica.

Mas, em qualquer dos casos, a regra única de avaliação de uma argumentação vem, como propõe Plantin, de dentro dela, ou seja, deriva da existência de um contra-discurso ${ }^{41}$.

Ter instrumentos para proceder a uma análise da argumentação poderá ser, nesse caso, uma ferramenta fundamental no gesto crítico para que remete a competência de produzir um contra-discurso e um bom ponto de partida para uma didáctica da argumentação que terá como seu pano de fundo o fomento da disciplina semiótica crítica de leitura e interacção com os discursos.

\section{REFERÊNCIAS BIBLIOGRÁFICAS}

AMOSSY, Ruth, 2006, L'argumentation dans le discours, Paris, Armand Colin. ANSCOMBRE, J-C., DUCROT, O., 1997, L'argumentation dans la langue, 3. ${ }^{\mathrm{a}}$ Ed., Bruxelles, Pierre Mardaga Editeur.

DIJK, Teun A. van, «The Study of Discourse» in DIJK, Teun A. van (Ed.), 1997, Discourse Studies. A Multidisciplinary Introduction. Vol. 1: Discourse as structure and process, London, Sage Publications.

DIJK, Teun A. van, 2004, From text grammar to critical discourse analysis, in http://www.discourses.org/OldArticles/From\%20text\%20grammar\% 20 to $\% 20$ critical $\% 20$ discourse $\% 20$ analysis.pdf

DIJK, Teun A. van, 2005, Discurso, Notícia e Ideologia. Estudos na Análise Crítica do Discurso, Porto, Campo das Letras.

41 «La discussion précédente tend à substituer à ces divers systèmes [o critério do auditório e a teoria das falácias] une approche immanente du dialogue, où la seule norme du discours est un contre-discours» (PLANTIN, C., «Analyse et critique du discours argumentatif» in KOREN, Roselyne e AMOSSY, Ruth (Org.), 2002, Après Perelman: quelles politiques pour les nouvelles rhétoriques?, L'Harmattan, p. 250). 
DUCROT, O., «Argumentation rhétorique et argumentation linguistique» in DOURY, M. e MOIRAND, S. (Org), L'argumentation aujourd'hui. Positions théoriques en confrontation, Paris, Presses Sorbonne Nouvelle.

GOODWIN, Jean, 2002, «Designing Issues» in EEMEREN, F. H. van e HOUTLOUSSER, P. (Eds), 2002, Dialectic and Rhetoric. The Warp and Woof Argumentation Analysis, Dordrecht, Kluwer Academic Publishers.

GOODWIN, Jean, 2007, «Argument Has No Function» in Informal Logic, vol. 27, n. ${ }^{\circ} 1$, pp. 69-90.

GRIZE, J.-B., «Raisonner en parlant» in, MEYER, M. (Ed.), 1986, De la métaphysique à la rhétorique, Bruxelles, Éditions de l'Université de Bruxelles.

GRIZE, J.-B., 1996, Logique naturelle \& communications, Paris, P.U.F..

GRIZE, J.-B., 1997, Logique et langage, Paris, Ed. Ophrys.

JACQUES, F., «Argumentation e stratégies discursives» in LAMPEREUR, A. (Ed.), 1991, L'argumentation, Mardaga, Liége.

JOHNSON, R.H. \& BLAIR, J. A., 2005, J.A., Logical Self-Defense, NY, Idebate Press.

MARTINS, Moisés de Lemos, 2002, Semiótica em http://hdl.handle.net/1822/996.

PLANTIN, C., "Analyse et critique du discours argumentatif» in KOREN, Roselyne e AMOSSY, Ruth (Org.), 2002, Après Perelman: quelles politiques pour les nouvelles rhétoriques?, Paris, L'Harmattan.

PLANTIN, C., «Situation des études de l'argumentation: de délégitimations en réinventions» in DOURY, M. e MOIRAND, S. (Org.), 2004, L'argumentation aujourd'hui. Positions théoriques en confrontation, Paris, Presses Sorbonne Nouvelle.

PLANTIN, C., 1998, «L'interaction argumentative» in Dialoganalyse VI, Tübingen, Max Verlag.

PLANTIN, C., 2005, L'argumentation, Paris, P.U.F..

RISSO, Mercedes Sanfelice e JUBRAN, Clélia Cândida A. Spinardi, 1988, Self-reflexive discourse: Metadiscoursive processing of the text. DELTA. [online]. 1998, vol. 14, no. spe [cited 2007-07-19]. Available from: http://www.scielo. br/scielo.php?script=sci_arttext\&pid=S0102-44501998000300015\& lng=en\&nrm=iso $>$. ISSN 0102-4450.

TOMLIN, Russell S., FORREST, Linda, PU, Ming Ming e KIM, Myung Hee, «Discourse Semantics», in DIJK, Teun van (Ed.), 1997, Discourse as structure and process, Sage Publications.

TOULMIN, S., 1958, The Uses of Argument, Cambridge, Cambridge University Press.

WILLARD, C. A., 1983, Argumentation and the Social Grounds of Knowledge, Alabama, The University of Alabama Press.

WILLARD, C. A., 1989, A Theory of Argumentation, Tuscaloosa/London, The University of Alabama Press. 